\title{
REVUE DE LA LITTERATURE INTERNATIONALE ET COMPTE-RENDU DE CONGRÈS
}

Avec la collaboration de :

\author{
J. BELAISCH \\ J.C. CZYBA \\ A. DEMOULIN \\ M. DROSDOWSKY \\ H. LEJEUNE \\ B. SALLE
}




\section{Revue de la littérature internationale}

\section{SPERMIOLOGIE-SPERMATOGENESE}

563 Compte-rendu du XIII Testis Workshop : Mécanismes moléculaires de régulation des cellules testiculaires.

H. LEJEUNE

574 Quelle est la longueur d'un spermatozoïde géant ?

S. PITNICK, G.S. SPICER, T.A. MARKON

Nature, v.375, 109, 11 mai 1995.

\section{ENDOCRINOLOGIE}

575 Expression et fonctionnement du récepteur LH/CG dans la prostate du rat E. Reiter, M.Mc NAMARA, J. Closse'T, G. HenNEN

Endocrinology, $136:$ 917-923, 1995.

575 Contribution de la dihydrotestostérone au comportement sexuel masculin C.S. MANTZORO, E.I. GIORGIADIS, D. TRICHOPOULOS BMJ, v.310, 1289-1291, 1995.

576 Fertilité des hommes exposés in utero au diethylstilbestrol

A.J. WILCOX, D.B. BAIRD, C.R. WEINBERG ET AL.

N.Engl.J.Med., v.332, 1411-1416, 1995.

\section{IMMUNOLOGIE}

578 Relation entre hypertension artérielle de la grossesse et durée des rapports sexuels avant la conception

P.Y. RobILLARD, J.C. HULSEY, J. PERIANIN ET AL.

The Lancet, v.344, 973-975, 1994.

\section{FECONDATION IN VITRO}

580 Le résultat de l'injection intracytoplasmique du spermatozoïde n'est en relation avec aucun des trois principaux paramètres du spermogramme Z.P. NAGY, J. LIU, H. JORIS ET AL.

Human Reprod., 10 (5), 1123-1129,1995.

582 Embryons viables obtenus par injection intraovocytaire de spermatides rondes

J. Tesarik, C. Mendoza, J. TestaRT

New Engl. J. Med., v.333, $n^{\circ} 8,525,1995$ 


\section{SPERMIOLOGIE SPERMATOGENESE}

\section{Mécanismes moléculaires de régulation des cellules testiculaires}

\author{
Compte-rendu du XIII ${ }^{\circ}$ Testis Workshop. \\ "Cellular and molecular regulation of testi- \\ cular cells" \\ 30 Mars - 2 Avril 1995. \\ Raleigh, North Carolina, USA.
}

Hervé LEJEUNE

INSERM-INRA U.418, Hôpital Debrousse \& Clinique Endocrinologique, Hôpital de l'Antiquaille, Lyon.

Les "TESTIS WORKSHOPS" se déroulent alternativement les années paires en Europe et les années impaires en Amérique du Nord. L'édition 1995 s'est tenue à Raleigh, en Caroline du Nord. Ce congrès a permis l'actualisation les connaissances au niveau moléculaire dans les principaux aspects de la physiologie testiculaire. Le programme a comporté 22 conférences dont les éléments principaux sont retranscrits ici. Pour les lecteurs souhaitant consulter les publications originales, nous avons recherché les principales références bibliographiques récentes correspondant aux travaux présentés.

La SESSION I : ANALYSE MOLECULAIRE DU CYCLE CELLULAIRE, n'avait qu'indirectement trait au testicule.

Dans la première conférence intitulée Événe. ments régulateurs précoces dans le cycle cellulaire de la levure, Michael MENDENHALL, de Lexington, KY, USA, a montré que la levure Saccharomyces cerevisiae représente un modèle d'étude à la fois de la mitose et de la méiose, plus facile à manipuler in vitro que les espèces supérieures. La description de la succession d'activation et d'inhibition de nombreuses protéines intracellulaires (cyclines, kinases ...) impliquées dans la régulation du cycle biologique de la levure (mitoses, méiose, fusion, sporulation ...), laisse entrevoir la complexité des phénomènes homologues dans les espèces supérieures.

Sous le titre Régulation du cycle cellulaire chez l'embryon précoce, Katherine I. SWEN-
SON, de Durham, NC, USA, a précisé que l'activation du complexe cyclin/p34cdc2 kinase, qui a lieu lors de l'entrée en mitose, se produit aussi lors de la méiose. La méiose met toutefois en jeu des composants spécifiques qui n'interviennent pas pendant les divisions mitotiques. Parmi ces composants spécifiques, se trouve c-mos, une serine/thréonine kinase nécessaire à la méiose. La synthèse et l'activation de c-mos dans l'ovocyte de grenouille Xenopus laevis est nécessaire à l'activation du complexe cyclin/p34cdc2 kinase avant la phase $\mathrm{M}$ des deux divisions méiotiques. A la suite de la méiose, c-mos est protéolysé et ne sera plus produit, ni chez l'embryon ni chez l'animal adulte. La progestérone qui est l'activateur physiologique de la méiose dans ce modèle entraîne, après liaison à des récepteurs membranaires, la synthèse de c-mos qui provoque l'activation du complexe cyclin/p34cdc2, l'activation de la cascade des MAP-kinases et la méiose. Des composés lipidiques interviennent aussi dans la méiose. L'activation de l'ovocyte par la progestérone provoque l'activation d'une sphingomyélinase qui produit du céramide. Celui-ci intervient dans l'activation de l'ovocyte et la reprise de la méiose.

\section{La SESSION II : REGULATION DE LA DIFFÉRENCIATION DES CELLULES GER. MINALES a débuté par la présentation de José MILLAN de La Jolla, CA, USA, intitulée Éta- blissement de lignées de cellules germinales murines pour l'étude de la spermatogénèse in vitro [1-3].}

Les propriétés immortalisantes de l'antigène grand $\mathrm{T}$ du virus SV40 (LTAg pour Large T antigen) ont été utilisées pour établir des lignées de cellules de Sertoli, de cellules péritubulaires, de cellules de Leydig, ainsi qu'une lignée de cellules germinales correspondant à un stade intermédiaire entre la spermatogonie $B$ et le spermatocyte. La co-transfection du LTAg et d'un mutant thermosensible de la protéine inhibitrice de la prolifération cellulaire p53 (tsp53) a permis d'obtenir d'autres lignées de cellules germinales. A la température non permissive de $39^{\circ} \mathrm{C}$ (à laquelle il n'y a pas d'expression de la protéine p53), les cellules GC-2spd(ts) se multiplient par mitose, par contre à $37^{\circ} \mathrm{C}$ ou $32^{\circ} \mathrm{C}$, les cellules montrent des signes morphologiques de différenciation avec apparition d'un granule proacrosomique et un axonème flagellaire. L'analyse en cytométrie de flux des cellules cultivées à $37^{\circ} \mathrm{C}$ 
montre un pic prédominant de cellules haploïdes, ce qui indique que des cellules ont effectué la méiose. Ainsi ces cellules immortalisées sont capables d'effectuer la méiose in vitro sans l'intervention de cellules de Sertoli. L'hypothèse avancée est que le rôle des cellules de Sertoli pourrait être d'initier une activation de la p53 dans les cellules germinales, leur permettant d'effectuer la méiose.

Frans Van der HOORN de Calgary, Alberta, Canada, a fait état de ses recherches concernant la Régulation de la transcription de gènes codant pour l'oncoprotéine mos et la protéine de la fibre dense externe RT7 pendant la spermatogénèse [4-8].

L'expression de c-mos dans les cellules germinales avant la méiose provient de l'utilisation de promoteurs spécifiques du testicule et de l'ovocyte. Le promoteur spécifique testiculaire de rat a été caractérisé. Un facteur de transcription spécifique du testicule vient s'y fixer. Un autre gène spécifique du testicule, le gène RT7, code pour une protéine majeure de la fibre dense externe du spermatozoïde de $27 \mathrm{kDa}$. Son promoteur lie 2 facteurs de transcription spécifiquement testiculaires. L'un est la protéine CREMt qui est exprimée dans les spermatides et qui, après activation par l'AMPc via la Proteine Kinase A, active le promoteur de RT7 en se liant à un élément de réponse à l'AMPc (CRE). L'autre est un facteur spécifique du testicule, appelé TTF-D. Ce facteur spécifique du testicule se lie non seulement au promoteur de RT7 mais est aussi le facteur spécifique du testicule se liant au promoteur de c-mos. On a donc ici un exemple de caractérisation d'un facteur de transcription spécifique du testicule régulant l'expression de plusieurs gènes spécifiques des cellules germinales.

Kwan Hee KIM de Pullman, WA, USA, a fait le point sur le Rôle de la vitamine A dans le développement des cellules germinales mâles [9, 10].

La vitamine A est nécessaire à la spermatogénèse chez les vertébrés. Dans les testicules d'animaux déficients en vitamine $\mathrm{A}$, les cellules germinales dégénèrent, il ne persiste que les spermatogonies $\mathrm{A}$ et les spermatocytes préleptotènes. A partir de l'injection de rétinol chez les rats déficients en vitamine $A$, la spermatogénèse reprend de manière synchronisée, à partir de ces 2 types cellulaires. Ceci suggère que les cellules restant dans le testicule lors du déficit en vitamine $\mathrm{A}$, sont arrêtées à un stade précis, vitamine A-dépendant, de leur développement. La localisation cellulaire du récepteur à l'acide rétinoïque RAR-a permet de déterminer quelle cellule répond au rétinol dans le testicule ; en effet, l'inactivation du récepteur RAR-a chez des souris transgéniques, entraîne un arrêt de la spermatogénèse avec une morphologie identique à celle des rats déficients en vitamine $A$. Le niveau des transcripts du RAR-a est maximum $1^{\circ}$ ) dans les cellules de Sertoli supportant les cellules en début de méiose et $2^{\circ}$ ) dans les spermatides rondes du stade VIII. Ces résultats suggèrent que la vitamine $\mathrm{A}$ agit $1^{\circ}$ ) dans les cellules de Sertoli pour stimuler la prolifération des spermatogonies A1 et l'initiation de la méiose des spermatocytes préléptotènes. $2^{\circ}$ ) dans les spermatides rondes au stade VIII, alors qu'elles initient leur transformation en spermatides allongées.

La SESSION III traitait des INTERACTIONS CELLULAIRES DANS L'EPITHELIUM SEMINIFERE, avec tout d'abord l'intervention de Pellegrino ROSSI, de Rome, Italie, intitulée Différentes formes et fonctions du récepteur c-kit et de son ligand pendant la spermatogénèse [11, 12$]$.

Pour les deux lignées de souris mutantes $\mathrm{W}$ et Sl, un des symptômes est la stérilité. Le locus $W$ code pour le récepteur membranaire de type tyrosine kinase c-kit et le locus Sl code pour son ligand Steel factor (SLF). L'ARNm de c-kit est exprimé à la fois dans les cellules germinales primordiales et dans les cellules germinales postnatales avec un niveau élevé d'expression dans les spermatogonies A. L'expression de c-kit s'arrête dans les stades méiotiques. Dans les stades haploïdes, un transcrit alternatif de petite taille a été mis en évidence, il code pour une protéine tronquée intracellulaire dont la fonction est encore inconnue. Ce transcrit alternatif est généré par un promoteur cryptique présent dans un intron et actif uniquement dans les spermatides rondes. Dans les spermatogonies A le récepteur c-kit de taille normale est la cible $\mathrm{du}$ SLF qui est produit par les cellules de Sertoli. Le SLF peut exister soit sous forme soluble soit sous forme transmembranaire, ces 2 formes sont codées par des ARNm différents, produits par splicing alternatif. La forme transmembranaire stimule la survie des cellules germinales 
primordiales dans la gonade embryonnaire. Dans le testicule post-natal, la stimulation des cellules de Sertoli par la FSH augmente les ARNm de la forme soluble de SLF. L'addition de forme soluble de SLF recombinant à des cultures enrichies en cellules germinales induit une augmentation de la synthèse d'ADN, spécifiquement dans les spermatogonies A. On voit donc qu'il existe des différences au niveau moléculaire du système de communication cellules germinales-cellules somatiques c-kit/SLF, lors de la mise en place des ébauches gonadiques et dans le testicule adulte.

James TSURUTA a ensuite fait état des travaux réalisés à Chapel Hill, NC, USA, concernant les Modifications de l'expression des gènes dans les cellules germinales par l'intermédiaire du récepteur à l'IGF-II/Mannose 6Phosphate [13, 14].

L"IGF-II/cation-independant mannose 6-phosphate receptor" est un récepteur multifonctionnel avec des sites de liaison distincts pour l'IGFII et le mannose 6-phosphate (M6P) portés par des glycoprotéines. Ce récepteur est impliqué dans le transport d'enzymes hydrolytiques porteuses de M6P vers les lysosomes, l'endocytose des M6P-glycoprotéines et la transduction du signal de l'IGF-II ou de facteurs de croissance porteurs de M6P. Ce récepteur est présent à la surface des cellules germinales, et en particulier au niveau des spermatogonies et des spermatocytes précoces. Le milieu conditionné des cellules de Sertoli provoque une augmentation dose-dépendante des niveaux du gène précoce cfos dans les cellules spermatogénétiques isolées de souris adultes. Cet effet est inhibé en présence de M6P, démontrant que cette modification est largement médiée par le récepteur à l'IGFII/M6P. Hybridation in situ et immunocytochimie confirment que l'IGF-II est présent dans le tube séminifère et peut se lier au récepteur à I'IGF-II/M6P des cellules germinales, et de fait, l'IGF-II augmente c-fos dans les spermatogonies. Ces résultats montrent que des ligands du récepteur à l'IGF-II/M6P, IGF-II mais aussi glycoprotéines porteuses de M6P, sont sécrétés par les cellules de Sertoli et peuvent moduler l'expression des gènes dans les cellules germinales.

LA SESSION IV : MACROMOLECULES ET ORGANELLES SPECIFIQUES DES CELLULES GERMINALES, a débuté par la présentation d'Erwin GOLDBERG d'Evanston, IL,
USA, portant sur les Macromolécules spécifiques du testicule. Aspects structural et fonctionnel pendant la spermatogénèse [15. 18 ].

Les événements moléculaires programmés qui surviennent à la mise en place et lors du déroulement de la spermatogénèse comportent l'activation et l'inactivation de nombreux gènes codant pour des protéines ayant des propriétés spécifiques du testicule. Les gènes exprimés pendant la spermatogénèse peuvent être classés en : 1) "gènes de ménage" ("housekeeping gènes") exprimés dans tous les tissus, 2) gènes exprimés uniquement dans le testicule (exemple : protamines et protéines de transition), 3) gènes codant pour des isoformes spécifiques au testicule d'enzymes ou de protéines somatiques (exemple : LDH-C4, PGK-2, ACE, CREMt, Cytochrome ct histones $\mathrm{H} 1$ et $\mathrm{TH} 2 \mathrm{~B}$ ). Ces protéines spécifiques sont soit codées par des loci distincts comme LDH-C et PGK-2, ou dérivent du même locus que leurs équivalents somatiques. Dans ce dernier cas, les gènes somatiques sont régulés de manière particulière et des $A R N m$ spécifiques au testicule sont élaborés à partir des gènes somatiques par 1) splicing alternatif, pour plusieurs oncogènes (c-alb, c-pim-1, c-mos, Nras) et plusieurs gènes non oncogènes (proenképhaline, Hox 1,4 et CREM) ; 2) utilisation de site d'initiation de la transcription et de promoteurs différents (GATA-1, ACE, Cytochrome c, farnesyl pyrophosphate synthetase) ; 3) utilisation de sites alternatifs de polyadénylation ( $\beta-1,4$-galactosyl-tranferrase, c-alb). Les mécanismes régulant l'expression des gènes lors de la spermatogénèse sont souvent définis de manière assez précise, mais il faut noter que la fonction des protéines codées par ces gènes reste souvent à définir.

Sous le titre Biologie cellulaire et moléculaire de nouvelles protéines du cytosquelette des spermatozoïdes $[19,20]$, Richard OKO de Montréal, Québec, Canada, a présenté la démarche qui l'a conduit à cloner et séquencer des protéines du cytosquelette du spermatozoïde.

La purification de protéines du spermatozoïde a permis la production d'anticorps qui ont permis de "screener" une banque de cDNA de testicule et d'isoler et de séquencer les cDNA codant pour une protéine de $15 \mathrm{kDa}$ de l'enveloppe périnucléaire, une protéine de $27 \mathrm{kDa}$ de la fibre dense 
externe et une protéine de $75 \mathrm{kDa}$ de la gaine fibreuse. Des études en Northern blot au cours $\mathrm{du}$ développement testiculaire et en hybridation in situ et immunocytochimie sur le testicule adulte ont permis de préciser la chronologie de la transcription et de la traduction de ces protéines dans les cellules haploïdes. Les ARNm de la protéine de $15 \mathrm{kDa}$ sont traduits en protéines dès les premiers stades des cellules haploïdes, avant l'arrêt de la transcription. La protéine se trouve autour de la vésicule acrosomique dans les spermatides de stade 2, elle s'attache ensuite à la membrane nucléaire (stade 4) pour se localiser spécifiquement entre les membranes acrosomique et nucléaire à partir du stade 8 . Par contre les ARNm des protéines de $27 \mathrm{kDa}$ de la fibre dense externe et de la protéine de $75 \mathrm{kDa}$ de la gaine fibreuse sont transcrits dans les cellules haploïdes mais ne sont traduits en protéines que plus tard, après une période de latence, dans les spermatides allongées. La connaissance des gènes codant pour ces protéines permettra de réaliser des expériences d'inactivation chez les souris transgéniques pour préciser le rôle de ces protéines.

Stephen KISTLER de Columbia, SC, USA, a présenté l'Analyse des promoteurs de la protéine de transition 1 (TP1) et de l'histone H1t (21-23).

Au cours de la spermatogénèse, on assiste à une modification des protéines de la chromatine des cellules germinales. Débutant dans les spermatogonies jusqu'aux spermatocytes, des histones spécifiques du testicule apparaissent et remplacent leurs équivalents somatiques. Plus tard, lors de la condensation de la chromatine pratiquement toutes les histones sont remplacées par une série de protéines de plus petite taille appelées protéines de transition nucléaires. Ces protéines de transition sont elles-mêmes rapidement remplacées par les protamines dans le noyau des spermatides tardives et des spermatozoïdes. Les gènes de l'histone spécifique du testicule H1t et de la protéine de transition TP1 ont été étudiés dans le but de comprendre les facteurs contrôlant leur transcription. Les ARN messagers de TP1 s'accumulent dans les spermatides rondes. Le promoteur de TP1 contient un élément de réponse à l'AMPc (CRE) qui est fonctionnel. Dans les extraits nucléaires de spermatides rondes une protéine appelée CREMt se lie au CRE du promoteur de TP1. Ainsi l'AMPc semble jouer un rôle dans l'activation de la transcription du gène de TP1. Les ARN messagers de l'histone spécifique du testicule, H1t s'accumulent seulement dans les spermatocytes pachytènes tardifs. En utilisant des souris transgéniques, il est montré qu'un fragment de seulement 141 paires de bases du promoteur de $\mathrm{H} 1$ t dirige l'expression de $\mathrm{H} 1 \mathrm{t}$ de rat spécifiquement dans le testicule des souris transgéniques. Ainsi lorsqu'une séquence du promoteur est associée à la toxine diphtérique $\mathrm{A}$ chez une souris transgénique, on obtient un arrêt de la spermatogénèse au niveau des spermatogonies.

\section{Dans la SESSION V : REGULATION DES EVENEMENTS MEIOTIQUES DANS LA SPERMATOGENESE, Catherine ATCHESON de Chicago, IL, USA, est revenue sur le modèle de la levure pour décrire les Mécanismes molé- culaires de contrôle de la méiose : les ensei- gnements tirés des levures.}

On estime à environ 200 le nombre de gènes nécessaires à la méiose, 40 ont été clonés et séquencés. La chronologie de leur expression peut-être étudiée précisément. Des cascades d'activation et d'inhibition de gènes interviennent dans le contrôle du cycle biologique des levures et l'orientation vers la méiose.

Peter MOENS, de Downsview, Ontario, Canada, a décrit L'axe central des chromosomes spermatocytaires chez la souris : organisation de l'ADN et des protéines [24].

Les études présentées ont été réalisées après purification d'une protéine du complexe synaptonémal de $125 \mathrm{kD}$ et d'une protéine de $30 \mathrm{kD}$ de la partie centrale (core) des chromosomes des spermatocytes pachytènes. Les anticorps contre ces protéines ont permis de "screener" une banque de cDNA de spermatocytes. Les cDNA reconnus ont été clonés et séquencés. L'organisation des protéines de la partie centrale et des protéines synaptonémales des chromosomes a été présentée avec des images en immunofluorescence avec double marquage.

La SESSION VI : ACTION ET PRODUCTION DES ANDROGENES, a été marquée par la succession de deux présentations concernant la localisation immunohistochimique des récepteurs aux androgènes dans le testicule. L'approche méthodologique des 2 équipes a été très similaire avec toutefois des résultats discordants sur un point sensible, la présence de récepteurs aux androgènes dans les cellules germinales. 
C'est tout d'abord, Carlos SUAREZ-QUIAN de Chicago, IL, USA, qui a présenté ses résultats sur la Distribution des récepteurs aux androgènes dans le testicule de rat [25].

La distribution du récepteur aux androgènes (RA) dans le testicule de rat adulte a été déterminée par immunohistochimie avec un anticorps polyclonal établi chez le lapin à partir des 21 acides aminés $\mathrm{NH} 2$ terminaux du récepteur aux androgènes de rat. De nombreux arguments en faveur de la spécificité de l'anticorps ont été présentés. Dans le compartiment interstitiel, le RA est détecté dans certaines cellules de Leydig et dans toutes les cellules musculaires lisses de la paroi des vaisseaux. Le RA est observé dans le noyau de toutes les cellules péritubulaires myoïdes. Pour les cellules de Sertoli, l'immunoréactivité $\mathrm{RA}$ dépend du stade de l'épithélium séminifêre : l'immunoréactivité devient évidente à la fin du stade VI et le marquage atteint un pic d'intensité au stade VII-VIII (stades reconnus comme androgénodépendants) puis disparaît complètement.

Le point de controverse est qu'une immunoréactivité spécifique est observée dans les noyaux des spermatides allongées au stade IX au moment où l'allongement du noyau a débuté mais où la condensation de la chromatine n'a pas encore débuté. Avec la condensation de la chromatine, le marquage disparaît dans le noyau mais apparaît dans le cytoplasme. Des observations similaires ont été effectuées chez la souris. Pendant la maturation testiculaire chez le rat, les RA sont d'abord détectés dans les cellules péritubulaires à 5 jours. L'immunoréactivité n'est détectable dans les cellules de Sertoli qu'à partir du jour 15 auquel toutes les cellules de Sertoli sont nettement marquées. Au jour 30 le marquage de type adulte (dépendant du stade de la spermatogenèse) devient évident.

Philippa SAUNDERS d'Edinburgh, RoyaumeUni, a ensuite fait part de ses résultats sur Le récepteur des androgènes dans le testicule: distribution de la protéine et contrôle de l'expression [26].

L'anticorps anti-récepteur aux androgènes a été obtenu chez le lapin à partir des 17 acides aminés NH2 terminaux du récepteur androgène humain. Dans le testicule de rat foetal les récepteurs androgènes sont détectés au 17 ème jour post-conception et uniquement dans les cellules interstitielles autour des tubes séminifères. Ensuite, l'abondance des récepteurs androgènes augmente dans les cellules péritubulaires et dans les cellules mésenchymateuses, mais la présence de récepteurs androgènes dans les tubes séminifères n'est identifiée qu'à partir du jour 20,5. Chez le rat nouveau-né le récepteur androgène est abondant dans le noyau des cellules péritubulaires et il apparaît dans les cellules de Sertoli et augmente. Une répartition dépendant du stade de la spermatogénèse s'établit à partir du jour 45 pour persister à l'âge adulte. Les récepteurs androgènes ont été détectés dans les testicules de marmouset, macaque et homme, mais contrairement au rat, il n'y a pas de différence significative d'abondance des récepteurs androgènes dans les cellules de Sertoli des tubes séminifères aux différents stades du cycle spermatogénétique. Des récepteurs aux androgènes sont présents dans les cellules de Sertoli de sujets présentant un syndrome des cellules de Sertoli isolées ou des azoospermies par troubles de la spermatogénèse. Chez le rat, l'arrêt de production d'androgène par l'EDS induit une perte des récepteurs androgènes qui sont restaurés par le traitement par la testostérone. L'altération de la spermatogénèse induite par des toxiques (Acide méthoxyacétique ou dinitrobenzène) ou par chauffage des testicules ne provoque pas de modification de l'immunoréactivité RA dans les cellules de Sertoli.

Contrairement à la présentation précédente, aucune immunoréactivité n'a été mise en évidence dans les cellules germinales. On note que les différences méthodologiques entre les 2 équipes sont peu importantes. On rappelle que physiologiquement, les arguments vont dans le sens d'un effet indirect des androgènes sur les cellules germinales par l'intermédiaire des cellules de Sertoli.

Andrew SHENKER du NIH à Bethesda, MD, USA, a fait le point sur, Les mutations activatrices du gène du récepteur à la $L H$ dans les testotoxicoses familiales [27, 28$]$.

La testotoxicose familiale est une forme de puberté précoce indépendante des gonadotrophines qui est transmise de manière autosomique dominante et d'expression limité aux sujets masculins. Les signes de puberté apparaissent habituellement à l'âge de 4 ans chez le garçon. La sécrétion de testostérone et l'hyperplasie des cellules de Leydig survient avec des 
niveaux prépubertaires de $\mathrm{LH}$. Le récepteur à la $\mathrm{LH}$ est un récepteur lié aux G protéines. $\mathrm{Sa}$ structure comporte un long domaine extracellulaire et 7 passages transmembranaires. La testotoxicose est liée à une mutation du récepteur à la LH qui serait activé spontanément en l'absence de l'hormone. Une mutation à l'état hétérozygote transformant l'Aps578 en Gly a été initialement mise en évidence chez les individus affectés dans 9 familles différentes. Différentes autres mutations ont été trouvées dans d'autres familles (Thr577->Ile, Met571->Ile). Pour montrer l'effet fonctionnel de ces mutations, le récepteur LH muté a été transfecté dans les cellules COS-7. Contrairement au récepteur LH sauvage, le récepteur muté induit, en l'absence de $\mathrm{LH}$, une production d'AMPc représentant environ $40 \%$ de la production maximale observée sous stimulation par la $\mathrm{LH}$. Le récepteur mutant garde la possibilité de lier et de répondre à des doses croissantes de LH. Le regroupement des mutations décrites dans la même région du récepteur, à l'extrémité cytoplasmique de l'hélice transmembranaire $n^{\circ} 6$, est en accord avec les résultats antérieurs montrant que les résidus acides aminés de cette région jouent un rôle critique dans le couplage du récepteur aux protéines G. L'Asp578 est conservé dans les récepteurs de toutes les hormones glycoprotéiques et pourrait stabiliser le récepteur dans une conformation inactive en participant à un pont hydrogène interhélice. La substitution d'acide aminé qui interrompt le pont interhélice peut permettre au récepteur de prendre spontanément une conformation active en l'absence d'hormone.

Au cours de la SESSION VII : MECANISMES DE TRANSPORT DANS LA SPERMATOGENESE, David ONG de Nashville, TN, USA, a fait le point sur le Rôle des protéines de transport dans le mouvement et le métabolisme des rétinoüdes dans le tube séminifère [29-31].

Le besoin absolu de vitamine A pour la spermatogénèse est bien établi. Le mouvement des rétinoïdes dans l'organisme met en jeu des protéines de transport à la fois intra- et extra-cellulaires. La retinol-binding protein (RBP) est la protéine de transport du rétinol du milieu extracellulaire, la cellular retinol-binding protein (CRBP) et la cellular retinoic acid-binding protein (CRABP) sont deux protéines intracellulaires de transport des rétinoïdes et des acides gras. Le métabolis- me du rétinol dans le testicule débute par la captation du rétinol du complexe rétinol-RBP par les cellules péritubulaires. Les cellules péritubulaires, riches en CRBP, vont fournir le rétinol à une molécule nouvellement synthétisée de RBP libérée pour atteindre le tube séminifère. La cellule de Sertoli, elle aussi riche en CRBP, peut alors internaliser le rétinol du complexe rétinolRBP. La cellule de Sertoli synthétise à son tour de nouvelles molécules de RBP-rétinol du côté apical pour fournir du rétinol aux cellules germinales du côté luminal de la barrière hémotesticulaire. L'une des destinées du rétinol est d'être internalisé dans les spermatides pour être converti en rétinyl ester et stocké. Ce stock de rétinoïdes pourrait avoir une fonction dans la maturation ultérieure des spermatozoïdes. Par ailleurs, la CRABP est localisée dans les spermatogonies et exclusivement localisée dans le cytoplasme, ce qui suggère un rôle pour protéger certains stades de la spermatogénèse de l'effet de l'acide rétinoïque.

Une mise au point sur les Mécanismes de transport des facteurs endocrines et paracrines dans le testicule [32-38] a été présentée par Richard SHARPE d'Edinburgh, UK.

Les mécanismes d'entrée, de sortie, de transport et de distribution des facteurs hormonaux et paracrines dans le testicule sont fondamentaux, ils n'ont été que peu explorés, peut-être parce que leur étude se fait principalement in vivo. Il existe 4 voies de transport dans le testicule, le sang, le fluide interstitiel, le fluide du tube séminifêre et la lymphe. La vascularisation est impliquée dans l'apport des nutriments et des hormones mais aussi dans l'élimination des produits élaborés par le testicule et des déchets. Le fluide interstitiel est formé par filtration par les vaisseaux capillaires. Sa formation et sa réabsorption sont largement gouvernées par la vasomotricité qui est sous le contrôle des androgènes et de plusieurs facteurs vasoactifs. Elle peut être modifiée par l'hypoxie, l'exposition à la chaleur, la présence d'une varicocèle et le tabagisme. Le fluide interstitiel représente le système par lequel toutes les hormones et tous les nutriments sont distribués dans le testicule et en particulier apportés au tube séminifere. Les cellules de Sertoli captent l'eau et les nutriments du fluide interstitiel et les apportent de manière sélective aux cellules germinales en élaborant le fluide $d u$ tube séminifère. Ce fluide apporte les 
nutriments aux cellules germinales et permet le transport des spermatozoïdes en dehors du testicule. La formation du fluide du tube séminifere et probablement sa réabsorption sont contrôlées par les androgènes. Le fluide interstitiel est le lieu de passage de messagers bioactifs entre les tubes séminifères, les cellules de Leydig, les macrophages et les vaisseaux. Diverses protéines de liaison comme l'ABP, les IGF-BPs ont un rôle de transport. L'ABP transporte les androgènes dans le fluide du tube séminifère jusqu'à l'épididyme et peut-être aux cellules germinales. Divers facteurs, en particulier la suppression des androgènes, la chaleur, le varicocèle et les facteurs vasoactifs peuvent interférer avec l'un ou l'autre des mécanismes d'échanges dans le testicule, provoquant des effets délétères sur la spermatogénèse. Il est ainsi probable que de tels mécanismes soient impliqués, de manière primitive ou secondaire dans des cas d'infertilité.

La SESSION VIII : BIOLOGIE MOLECULAIRE ET CELLULAIRE DE LA CELLULE DE LEYDIG a tout d'abord permis à Matthew HARDY de New York, NY, USA, de faire le point sur la Régulation hormonale de la différenciation des cellules de Leydig depuis les cellules précurseurs mésenchymateuses [39.42].

La différenciation des cellules de Leydig passe par deux stades identifiables : $1^{\circ}$ ) des précurseurs fusiformes qui se différencient au 14 ème jour post-partum et sont caractérisés par une expression faible de protéines spécifiques des cellules de Leydig, récepteur à la $\mathrm{LH}$ et $3 \beta$ hydroxystéroïde déhydrogénase et $2^{\circ}$ ) des cellules de Leydig immatures qui se différencient entre les 14 et $28^{\circ}$ jours post-partum et sont caractérisées par un réticulum endoplasmique lisse abondant. Elles produisent plus d'androgènes $5 \alpha$-réduits que de testostérone. La maturation des cellules de Leydig immatures en cellules de Leydig adulte se produit vers le $56^{\circ}$ jour avec augmentation de l'expression des enzymes de la biosynthèse de la testostérone et d'une diminution du métabolisme de la testostérone par la $5 \alpha$-réductase et la $3 \alpha$-hydroxystéroïde déhydrogenase ( $3 \alpha-\mathrm{HSD}$ ). La LH est nécessaire tout au long de la différenciation, mais de plus, les androgènes facilitent, via leur récepteur, la conversion des précurseurs en cellules de Leydig immatures en augmentant le niveau des ARNm du récepteur à la LH et de la 3a-HSD. L'IGF-I a un rôle dans la conversion des cellules de Leydig immatures en cellule de Leydig adultes comme le montre la délétion ciblée du gène de l'IGF-I chez la souris, ce qui aboutit à des cellules de Leydig produisant des stéroïdes "immatures" comme androstènedione. Enfin l'estradiol produit par les précurseurs des cellules de Leydig sous l'influence de facteurs paracrines issus des cellules de Sertoli, paraît pouvoir retarder l'acquisition de la fonction stéroïdogénique des cellules de Leydig en cours de différenciation.

La Régulation de l'expression du gène CYP17 pendant le développement et sous l'influence de l'AMP cyclique [43-46], a été exposée par Michael WATERMAN de Nashville, TN, USA.

La 17 $\alpha$-hydroxylase/17-20 lyase représente un carrefour clé dans la biosynthèse des stéroïdes. Dans la surrénale, l'activité $17 \alpha$-hydroxylase de l'enzyme est essentielle pour la production de cortisol. Dans les gonades, l'activité 17-20 lyase après la $17 \alpha$-hydroxylation est nécessaire à la production d'androgènes. Les deux activités sont catalysées par un site commun du cytochrome $\mathrm{P} 450 \mathrm{c} 17$, dérivé du gène CYP17. La régulation du CYP17 dans la surrénale et dans les gonades est multifactorielle, comportant des processus liés au développement, tissu-spécifiques et dépendants de l'AMPc. L'expression précoce dans le testicule est essentielle pour la production de testostérone et le développement du phénotype masculin. Par contre, dans la surrénale, de grandes variations existent selon les espèces. Dans l'espèce humaine, l'expression surrénalienne de CYP17 survient de manière précoce et est constante pendant la vie foetale. Chez les bovins et ovins l'expression de CYP17 est observée dans la surrénale foetale de manière précoce mais disparaît à mi-gestation et réapparaît au dernier trimestre. Elle est étroitement liée à la production foetale d'ACTH. Chez le lapin et la souris, l'activité du P450c17 est nettement détectable dans la surrénale foetale mais pas chez l'adulte. Chez la souris, l'expression du CYP17 survient après l'apparition de SF-1, facteur de transcription spécifique des organes stéroïdogéniques, aussi bien dans le testicule que dans la surrénale. Après la naissance, la régulation principale de CYP17 se fait via les hormones polypeptidiques ante-hypophysaire, ACTH pour la surrénale LH pour le testicule. Cette régulation est 
médiée par l'AMPc et la protéine kinase A. Deux éléments de réponse à l'AMPc sont impliqués dans le contrôle de la transcription du CYP17 par l'ACTH. On suppose que le même mécanisme a lieu dans le testicule avec la LH. Des processus post-transcriptionnels régulent aussi l'activité du P450c17, en particulier, le cytochrome b5 active l'activité $\Delta 4$ 17,20-lyase favorisant la production d'androgènes.

Keith PARKER de Durham, NC, USA, a montré que Le récepteur nucléaire $S F-1$ est essentiel à plusieurs niveaux du système reproducteur [47-51].

L'analyse de la régulation de l'expression des gènes des cytochromes $\mathrm{P} 450$ des hydroxylases de stéroïdes a permis d'identifier un récepteur nucléaire orphelin, appelé SF-1 (pour Steroidogenic Factor 1), qui contribue à la coordination de leur expression. Quand on analyse l'ontogénie de l'expression de SF1 dans l'embryon de souris, on trouve que les transcripts sont présents dans les surrénales et les gonades depuis les stades les plus précoces de l'organogenèse. Ensuite, les ARNm de SF-1 persistent dans le testicule en développement mais n'est par contre pas exprimé dans l'ovaire, révélant un dimorphisme sexuel pendant le développement gonadique. SF1 s'exprime aussi dans l'hypophyse antérieure et le diencéphale foetal qui donne l'hypothalamus, ce qui suggère d'autres rôle dans la reproduction. Pour étudier le rôle de SF-1 chez la souris entière, l'interruption ciblée du gène de SF-1 a été utilisée. Les animaux déficients en SF-1 sont nés avec la fréquence attendue, montrant que SF-1 n'est pas nécessaire à la survie embryonnaire. Par contre, tous les animaux meurent peu de temps après la naissance en raison d'un déficit en glucocorticoïdes. L'analyse des animaux déficients montre une agénésie des surrénales et des gonades, des déficits spécifiques de l'expression de plusieurs marqueurs des cellules gonadotropes hypophysaires et une absence de noyau ventromédian de l'hypothalamus. Ces résultats établissent le rôle essentiel du gène codant pour SF-1 à de multiples niveaux de l'axe reproducteur. Les efforts se poursuivent pour identifier les gènes qui interviennent en amont et en aval de SF-1 dans la cascade complexe d'événements conduisant à la différenciation sexuelle et au développement gonadique.

La SESSION IX intitulée REGULATION DE LA STEROÏDOGENESE était consacrée aux derniers développements des recherches concernant le mécanisme de la réponse aiguë des cellules stéroïdogènes à leur hormone stimulante hypophysaire.

Douglas STOCCO de Lubbock, TX, USA, a présenté la Caractérisation de la protéine responsable de la régulation aiguë de la stéroïdogénèse dans les cellules de Leydig tumorales de souris [52-54].

L'étape limitante, hormono-régulée, dans la stéroïdogénèse est la conversion du cholestérol en pregnénolone par le système de l'enzyme "cholesterol side chain cleavage" qui est localisée sur la membrane interne de la mitochondrie. L'étape régulée dans la réponse aiguë à la stimulation hormonale des cellules stéroïdogéniques est la fourniture du cholestérol à la "cholesterol side chain cleavage" au niveau de la membrane interne de la mitochondrie. Il a été établi, il y a plus de trente ans que ce transfert du cholestérol nécessite une synthèse protéique de novo. L'identification de la (ou des) protéine(s) impliquée(s) restait à faire. Le cDNA codant pour cette protéine a été cloné récemment et il a été montré que cette protéine, nommée StAR (pour Steroidogenic Acute Regulatory), est mitochondriale et induite par la LH dans les cellules de Leydig tumorales de souris MA-10. Le cDNA complet pour StAR a un cadre ouvert de lecture qui code pour une protéine de $32 \mathrm{kDa}$ dont les 25 premiers acides aminés sont caractéristiques d'une séquence qui dirige la protéine vers la mitochondrie. Il a été établi que l'expression de StAR induit la production de stéroïdes dans les cellules MA-10 en l'absence de stimulation hormonale, et que sa synthèse de novo est essentielle pour la production de stéroïdes induite par stimulation hormonale. La protéine StAR ne s'exprime que dans les tissus stéroïdogéniques avec un haut niveau d'expression dans la surrénale, l'ovaire, le testicule. Enfin, il a été montré que des mutations dans le gène de StAR sont la cause des cas les plus sévères d'hyperplasie congénitale des surrénales. Les sujets atteints par cette maladie létale sont incapables de synthétiser des stéroïdes et ont de grandes quantités d'ester de cholestérol dans les surrénales et les gonades. Les cDNA isolés chez ces patients et exprimés dans les cellules COS 1 sont incapables de stimuler la production de stéroïdes alors que l'expression du cDNA humain normal de StAR provoque une augmentation de la pro- 
duction de stéroïde, ce qui souligne le rôle indispensable de la protéine StAR dans la stéroïdogénèse.

Vassilios PAPADOPOULOS de Washington DC, USA, a présenté ses travaux portant aussi sur cette étape initiale de la stéroïdogénèse : $\boldsymbol{L}$ 'inhibiteur de la liaison du diazépam et le récepteur périphérique aux benzodiazépines : rôle dans la biosynthèse des stéroïdes [55$60]$.

Il a été précédemment démontré que le récepteur périphérique aux benzodiazépines (PBR : peripheral benzodiazepine receptor) est couplé à la stimulation de la stéroïdogénèse par les hormones en régulant le transport du cholestérol au cytochrome P450scc. Le PBR est constitué d'un complexe de 5 protéines de $18 \mathrm{kDa}$ et d'une protéine de $34 \mathrm{kDa}$ "voltage dependant-anion channel", site de liaison des benzodiazépines au complexe. Ce complexe se localise préférentiellement aux sites de contacts entre les membranes interne et externe de la mitochondrie. Le ligand endogène du récepteur périphérique aux benzodiazépines est le polypeptide, appelé DBI pour diazepam binding inhibitor. La stimulation par la LH induit l'apparition rapide et transitoire de sites de liaison de plus haute affinité pour les benzodiazépines de manière concomitante avec l'augmentation du taux de transfert du cholestérol au cytochrome P450scc et de la formation de stéroïdes. L'introduction d'une mutation nulle dans le gène du récepteur périphérique aux benzodiazépines fait qu'il n'y a plus de liaison des ligands aux PBR et la production de stéroïdes est alors dramatiquement réduite. La stimulation hormonale fait apparaître des sites de haute affinité de liaison du DBI au PBR. La liaison des ligands aux sites de haute affinité provoque une augmentation du transport du cholestérol au P450scc et de la stéroïdogénèse.

Les mécanismes d'activation aiguë de la fourniture de cholestérol au cytochrome P450scc lors de la stimulation aiguë par les hormones hypophysaire ACTH ou LH pourraient être doubles, faisant d'abord intervenir l'interaction DBI-PBR puis dans les premières heures la protéine StAR.

Ainsi le Testis Workshop de Raleigh a-t-il permis de faire le point sur l'état d'avancement en 1995 des recherches concernant la biologie testiculaire à l'échelon moléculaire et cellulaire.
L'édition 96 sera le 9th European Testis Workshop et aura lieu à Geilo en Norvège du 14-19 Avril 1996.

Remerciements : L'auteur tient à remercier les Laboratoires Sérono-France SA pour leur participation financière aux frais de voyage.

\section{REFERENCES}

1. Hofmann MC, Narisawa S, Hess Ra, Millan JL. : Immortalization of germ cells and somatic testicular cells using the SV40 Large T-Antigen. Exp Cell Res. $1992 ; 201: 417-435$.

2. Hofmann MC, Hess RA, Goldberg E, Millan JL. : Immortalized germ cells undergo meiosis in vitro. Proc Natl Acad Sci USA. 1994 ; 91 : 5533-5537.

3. Hofmann MC, ABramian D, MiLLAN JL.A : haploid and a diploid cell cycle coexist in an in vitro immortalized spermatogenic cell line. Develop Gen. $1995 ; 16: 119-127$.

4. VANDERHoorn FA, SPIEgel JE, Mayliepfenninger MF, NORDEEN SK. : A $43 \mathrm{kD}$ c-mos protein is only expressed before meiosis during rat spermatogenesis. Oncogene. 1991 ; 6 : 929-932.

5. VANDERHOORN FA. : Identification of the testis cmos promoter - specific activity in a seminiferous tubule-derived extract and binding of a testis-specific nuclear factor. Oncogene. $1992 ; 7: 1093$ 1099.

6. Delmas V, Vanderhoorn F, Mellstrom B, Jegou B, SASSONECORSI P. : Induction of crem activator proteins in spermatids - Down-Stream targets and implications for haploid germ cell differentiation. Molec Endocrinol. $1993 ; 7$ : 1502-1514.

7. Higgy Na, Pastoor T, Renz C, Tarnasky Ha, VanDERHOORN FA. : Testis-specific RT7 protein localizes to the sperm tail and associates with itself Biol Reprod. 1994 ; 50 : 1357-1366.

8. Higgy NA, ZaCKSON SL, VANDERHoORn FA. : Cell interactions in testis development : overexpression of c-mos in spermatocytes leads to increased germ cell proliferation. Develop Gen. 1995 ; 16 : 190-200.

9. WANG ZQ, KIM KH. : Vitamin-A-Deficient testis germ cells are arrested at the end of S-Phase of the cell cycle - a molecular study of the origin of synchronous spermatogenesis in regenerated seminiferous tubules. Biol Reprod. 1993 ; 48 : 1157-1165.

10. WANG $Z Q$, Kıм KH. : Retinol differentially regulates male germ cell-associated kinase (mak) messenger ribonucleic acid expression during spermatogenesis. Biol Reprod. 1993 ; 49 : 951-964. 
11. Rossi $\mathbf{P}$, Dolci $\mathbf{S}$, Albanesi C, Grimaldi P, Ricca R, GeremLA R. : Follicle-Stimulating hormone induction of steel factor (SLF) messenger RNA in mouse sertoli cells and stimulation of DNA synthesis in spermatogonia by soluble SLF. Develop Biol. $1993 ; 155: 68-74$.

12. Geremia R, Albanesi C, Dolct S, Giustizieri L, Grimaldi P, Grippo P, Orlando PA, Piscitelli D, Rossi P. : C-kit receptor function and regulation by SLF in the post-natal testis.In " Cell and Molecular Biology of the Testis". Dufau, Fabbri and Isidori eds. Frontiers in Endocrinology, Ares-Serono Symposia Publications. 1994 ; 5 : 189-198.

13. Obrien DA, Gabel CA, Eddy EM. : Mouse Sertoli cells secrete mannose 6-Phosphate containing glycoproteins that are endocytosed by spermatogenic cells. Biol Reprod. 1993 ; 49 : 1055-1065.

14. Obrien DA, Welch JE, Fulcher KD, Eddy EM. : Expression of mannose 6-Phosphate receptor messenger ribonucleic acids in mouse spermatogenic and Sertoli cells. Biol Reprod. 1994 ; 50 : 429-435.

15. Salehiashtiant K,Goldberg E. : Differences in regulation of testis specific lactate dehydrogenase in rat and mouse occur at multiple levels. Mol Reprod Develop. 1993 ; 35 : 1-7.

16. Cooker LA, Brooke CD, Kumari M, Hofmann MC, MillaN JL, GOLdBERG E. : Genomic structure and promoter activity of the human testis lactate dehydrogenase gene. Biol Reprod. 1993 ; 48 : 1309 1319 .

17. ZHOU WT, XU JH, GoldBERG E. : A 60-bp core promoter sequence of murine lactate dehydrogenase $c$ is sufficient to direct testis-specific transcription in vitro. Biol Reprod. 1994 : 51 : 425-432.

18. BonNy C, GoldBerg E. : The CpG-rich promoter of human LDH-C is differentially methylated in expressing and nonexpressing tissues. Develop Gen. $1995 ; 16: 210-217$.

19. OKo R, Morales CR. : A novel testicular protein, with sequence similarities to a family of lipid binding proteins, is a major component of the rat sperm perinuclear theca. Develop Biol. 1994 ; 166 : 235-245.

20. Gu W, Kwon Y, Oko R, Hermo L, Hecht NB. : Poly (A) binding protein is bound to both stored and polysomal mRNAs in the mammalian testis. Mol Reprod Develop. 1995 ; 40 : 273-285.

21. KREMER EJ, KISTLER WS. : Localization of mRNA for testis-specific histone $\mathrm{H} 1 \mathrm{t}$ by in situ hybridization. Exp Cell Res. 1991 ; $197: 330-332$.

22. Alfonso PJ, W. S. KISTLER WS. : Immunohistochemical localization of spermatid nuclear transition protein-2 in the testes of rats and mice. Biol Reprod. 1993 ; 48 : 522-529.
23. Kistler MK, Sassonecorsi P, Kistler WS. : Identification of a functional cyclic adenosine $3^{\prime}, 5^{\prime}-$ monophosphate response element in the 5'-flanking region of the gene for transition protein 1 (TP1), a basic chromosomal protein of mammalian spermatids. Biol Reprod. 1994 ; 51 : 1322-1329.

24. Dobson MJ, Pearlman RE, Karaiskakis A, Spyropoulos B, Moens PB. : Synaptonemal complex proteins : occurrence, epitope mapping and chromosome disjunction. J Cell Sci. 1994 ; 107 : 2749-2760.

25. Vornberger W, Prins G, Musto NA, SuarezQULAN CA. : Androgen receptor distribution in rat testis - new implications for androgen regulation of spermatogenesis. Endocrinology. $1994 ; 134: 2307$ 2316.

26. Bremner WJ, Millar MR, Sharpe RM, Saunders PTK. : Immunohistochemical localization of androgen receptors in the rat testis: evidence for stagedependent expression and regulation by androgens. Endocrinology. 135 (3) : 1227-1234, 1994.

27. Shenker A, Laue L, Kosugi S, Merendino JJ, MiNeGiShI T, CUTLER GB. : A constitutively activating mutation of the luteinizing hormone receptor in familial male precocious puberty. Nature. 1993 ; $365: 652-654$.

28. Kosugi S, SHenker A. : Characterization of heterogeneous mutations causing constitutive activation of the luteinizing hormone receptor in familial male precocious puberty. Hum Mol Gen. 1995 ; 4 : 183-188.

29. Davis JT, ONG DE. : Synthesis and Secretion of Retinol-Binding Protein by Cultured Rat Sertoli Cells. Biol Reprod. 1992 ; 47 : 528-533.

30. SchmiтT MC, ONG DE. : Expression of cellular Retinol-Binding protein and Lecithin-Retinol acyltransferase in developing rat testis. Biol Reprod. $1993 ; 49$ : $972-979$.

31. DAvis JT, ONG DE. : Retinol processing by the peritubular cell from rat testis. Biology of Reproduction. $1995 ; 52: 356-364$

32. SHARPE RM. : Monitoring of Spermatogenesis in Man - Measurement of Sertoli Cell-Secreted or Germ Cell-Secreted Proteins in Semen or Blood. Int J Androl. $1992 ; 15: 201-210$.

33. Maddocks S, Kerr JB, Allenby G, Sharpe RM. : Evaluation of the Role of Germ Cells in Regulating the Route of Secretion of Immunoactive Inhibin from the Rat Testis. J Endocrinol. 1992 ; 132 : 439.

34. Kerr JB, Millar M, Maddocks S, Sharpe RM. : Stage-Dependent changes in spermatogenesis and sertoli cells in relation to the onset of spermatogenic failure following withdrawal of testosterone. Anatomical Record. 235(4) : 547-559, 1993. 
35. Kerr JB, Savage GN, Millar M, Sharpe RM. : Response of the seminiferous epithelium of the rat testis to withdrawal of androgen - evidence for direct effect upon intercellular spaces associated with sertoli cell junctional complexes. Cell Tissue Res. $1993 ; 274$ : 153-161.

36. Maddocks S, Hargreave TB, Reddie K, Fraser HM, KERR JB, SHARPE RM. : Intratesticular hormone levels and the route of secretion of hormones from the testis of the rat, guinea pig, monkey and human. Int J Androl. $1993 ; 16: 272-278$.

37. Sharpe RM, KerR JB, Mckinnell C, Millar M. : Temporal relationship between androgen-dependent changes in the volume of seminiferous tubule fluid, lumen size and seminiferous tubule protein secretion in rats. J Reprod Fertil. 1994 ; 101 : 193198.

38. MCLaren TT, Foster PMD, Sharpe RM. : Identification of stage-specific changes in protein secretion by isolated seminiferous tubules from rats following exposure to short-term local testicular heating. J Reprod Fertil. 1994 ; 102 : 293-300.

39. Gelber SJ, Hardy MP, Mendishandagama SMLC, Casella SJ. Effects of insulin-like growth factor-I on androgen production by highly purified pubertal and adult rat Leydig cells. J Androl. 1992 ; 13 : 125-130.

40. Shan LX, Phillips DM, Bardin CW, Hardy MP. : Differential regulation of steroidogenic enzymes during differentiation optimizes testosterone production by adult rat Leydig cells. Endocrinology. $1993 ; 133: 2277-2283$.

41. Shan LX, HARdy MP. : Developmental Changes in Levels of Luteinizing Hormone Receptor and Androgen Receptor in Rat Leydig Cells. Endocrinology. $1992 ; 131: 1107-1114$.

42. Shan LX, Hardy DO, Catterall JF, Hardy MP. : Effects of luteinizing hormone (LH) and androgen on steady state levels of messenger ribonucleic acid for $\mathrm{LH}$ receptors, androgen receptors, and steroidogenic enzymes in rat leydig cell progenitors in vivo. Endocrinology $1995 ; 136: 1686-1693$.

43. Yanase T, Imai T, Simpson ER, Waterman MR. : Molecular basis of 17alpha-hydroxylase/17,20lyase deficiency. J Steroid Biochem Mol Biol. 1992 ; 43 : 973-979.

44. WATERMAN MR, KeENEY DS. : Genes involved in androgen biosynthesis and the male phenotype. Hormone Res. 1992 ; 38 : 217-221.

45. Fevold HR, IVANovitch JD, Zanger UM, WaterMAN MR. : The sequence of the 5'-End of the rat CYP17 gene, the transcription initiation site and a comparison with the homologous genes of other species. Mol Cell Endocrinol.1993 ; 95 : 95-100.
46. Katagiri M, Kagawa N, Waterman MR. : The role of cytochrome $b(5)$ in the biosynthesis of androgens by human p450c17. Arch Biochem Biophys. 1995 ; $317: 343-347$.

47. Lynch JP, Lala DS, Peluso JJ, Luo W, Parker $\mathrm{KL}$, WHITE BA. : Steroidogenic factor-1, an orphan nuclear receptor, regulates the expression of the rat aromatase gene in gonadal tissues. Mol Endocrinol. $1993 ; 7: 776-786$.

48. Clemens JW, LaLA DS, Parker KL, Richards JS. : Steroidogenic Factor-I binding and transcriptional activity of the cholesterol Side-Chain cleavage promoter in rat granulosa cells. Endocrinology. 1994 ; 134 : 1499-1508.

49. Luo XR, IKeda YY, Parker KL. : A cell-specific nuclear receptor is essential for adrenal and gonadal development and sexual differentiation. Cell. $1994 ; 77$ : 481-490.

50. Ingraham HA, LaLa DS, Ikeda Y, Luo XR, Shen WH, Nachtigal MW, Abbud R, Nilson JH, Parker KL. : The nuclear receptor steroidogenic factor 1 acts at multiple levels of the reproductive axis. Gen Develop. $1994 ; 8: 2302-2312$.

51. Ikeda Y, Luo XR, Abbud R, Nilson JH, Parker $\mathrm{KL}$. : The nuclear receptor steroidogenic factor 1 is essential for the formation of the ventromedial hypothalamic nucleus. Mol Endocrinol. 1995 ; 9 : 478-486.

52. STocco DM. : Further Evidence That the Mitochondrial Proteins Induced by Hormone Stimulation in MA-10 Mouse Leydig Tumor Cells Are Involved in the Acute Regulation of Steroidogenesis. J Steroid Bioch Mol Biol. 1992 ; 43(4) : 319333.

53. Clark BJ,Wells J, KING SR, Stocco DM. : The purification, cloning, and expression of a novel luteinizing hormone-induced mitochondrial protein in MA-10 mouse leydig tumor cells - characterization of the steroidogenic acute regulatory protein (stAR). J Biol Chem. 1994 ; 269 : 28314-28322.

54. Lin D, Sugawara T, Strauss JF, Clark BJ, Stocco DM, Rogol A, MiLLER WL. : Role of steroidogenic acute regulatory protein in adrenal and gonadal steroigenesis. Science. $1995 ; 267$ : 1828-1831.

55. Papadopoulos V. : Peripheral-Type Benzodiazepine/Diazepam binding inhibitor receptor - biological role in steroidogenic cell function. Endocrine Rev. $1993 ; 14: 222-240$.

56. Boujrad N, Hudson JR, Papadopoulos V. : Inhibition of Hormone-Stimulated steroidogenesis in cultured Leydig tumor cells by a cholesterol-linked phosphorothioate oligodeoxynucleotide antisense to diazepam-binding inhibitor. Proc Natl Acad Sci USA. 1993 ; 90 : 5728-5731. 
57. Garnier M, Dimchev AB, Boujrad N, Price JM, Musto NA, PAPADOPOULOS V. : In vitro reconstitution of a functional peripheral-type benzodiazepine receptor from mouse Leydig tumor cells. Mol Pharmacol. $1994 ; 45: 201-211$.

58. Garnier M, Boujrad N, OGwuegbu SO, Hudson JR, Papadopoulos V. : The polypeptide diazepambinding inhibitor and a higher affinity mitochondrial peripheral-type benzodiazepine receptor sustain constitutive steroidogenesis in the R2C leydig tumor cell line. J Biol Chem. 1994 ; 269 : 2210522112 ,

59. Papadopoulos V, Boujrad N, Ikonomovic MD, Ferrara P, Vidic B. : Topography of the Leydig cell mitochondrial peripheral-type benzodiazepine receptor. Mol Cell Endocrinol. 1994 ; 104 : R5-R9.

60. Boujrad N, Gaillard JL, M. Garnier M, PapadoPOULOS V. : Acute action of choriogonadotropin on leydig tumor cells: induction of a higher affinity benzodiazepine-binding site related to steroid biosynthesis. Endocrinology. 1994 ; 135 : 1576-1583.

\section{Quelle est la longueur d'un spermatozoïde géant ?}

\section{S. PITNICK*, G.S. SPICER**, T.A. MARKON***}

* Department of Biological Sciences, Bowling Grenn State University, Ohio, USA ; ** Institute of Molecular Medical Sciences, Palo Alto, California, USA ; *** Department of Zoology, Arizona State University, Tempe, USA

Nature, V. 375, p 109; 11 mai 1995

Cooper avait signalé en 1950 que le spermatozoïde de Drosophila melanogaster a une longueur de $1,76 \mathrm{~mm}$ soit 300 fois plus que le spermatozoïde humain.

Nous avons nous-mêmes découvert que Drosolphila bigurca produit des spermatozoïdes longs de $58,29 \pm 0,66 \mathrm{~mm}$; chaque gamète est environ 20 fois plus long que la mouche qui le produit.

L'existence de tels spermatozoïdes pose un certain nombre de problèmes et est en contradiction avec les idées reçues sur l'évolution des sexes (anisogamie) et la généreuse distribution des spermatozoïdes. La drosophile répartit ses spermatozoïdes avec parcimonie et beaucoup de soins chez plusieurs femelles.

La fabrication de ces spermatozoïdes implique d'importantes dépenses énergétiques dans des testicules qui correspondent à $11 \%$ du poids sec du mâle. La maturation sexuelle du mâle est de 17 jours, alors que celle de la femelle n'est que de 7 jours.

Quels peuvent être les avantages de tels spermatozoïdes en ce qui concerne la sélection ? Chez certaines espèces de drosophiles le spermatozoïde pénètre entièrement dans l'ovocyte, chez d'autres non. On peut imaginer que le spermatozoïde géant apporte à l'œuf une grande quantité d'ADN mitochondrial paternel.

\section{Commentaires : J.C. CZYBA}

Le lecteur curieux des choses de la nature s'émerveillera avec moi devant ces petites mouches qui produisent de si grands spermatozoïdes. Si l'évolution avait choisi de gratifier l'homme plutôt que la drosophile, nos spermatozoïdes mesureraient quelque 150 mètres.

Quoi qu'il en soit, et tout en sachant que comparer la mouche à l'homme est hasardeux, on ne peut s'empêcher de s'interrroger sur la signification de tels gamètes et en particulier de leurs mitochondries qui ne jouent pas de rôle dans les battements du flagelle puisque celui-ci est immobile. D'ailleurs le rôle des mitochondries du spermatozoïde humain n'est pas non plus complétement élucidé dans la mesure où son métabolisme énergétique consomme normalement très peu d'oxygène. 


\section{ENDOCRINOLOGIE}

\section{Expression et fonctionnement du récepteur $\mathrm{LH} / \mathrm{CG}$ dans la prostate de rat}

E. Reiter, M. McNamara, J. Closset, G. Hennen

Endocrinology, 136 : 917-923, 1995.

Depuis 4-5 ans, on a commencé à mettre en évidence le récepteur LH/CG dans des tissus cibles tels que les trompes, les membranes fotales, le cordon ombilical, l'utérus, le placenta, la thyroïde, le cerveau et dans la présente publication la prostate.

Ceci a été rendu possible grâce à l'utilisation du DNA complémentaire du récepteur et son amplification par PCR.

La présence d'un récepteur semblable à celui du testicule $(93 \mathrm{KDa})$ a été décelée dans les cellules épithéliales de prostate par immunoblotting en utilisant un anticorps polyclonal. Le récepteur est fonctionnel car d'une part il est capable de lier l'hCG et d'autre part il répond en provoquant la production, dose dépendante, de cAMP dans un explant prostatique.

Cette publication montre donc la présence d'un récepteur $\mathrm{LH} / \mathrm{CG}$ dans les lobes dorsal, latéral et surtout ventral de la prostate alors que classiquement ce récepteur est limité aux gonades. Néanmoins, la quantité de transcrit est nettement plus faible au niveau de la prostate comparée à celle mesurée dans l'ovaire et le testicule.

Reste à déterminer, sur le plan physiologique, l'importance de ce circuit court (intracrine) par rapport au circuit long (endocrine). Les auteurs émettent l'hypothèse d'une implication dans le développement ontogénique de la glande.

Cette publication ouvre un nouveau chapitre sur le rôle au niveau des tissus cibles des hormones glycoprotéiques en rapport avec la similitude structurale de leurs sous-unités avec certains facteurs de croissance.

(M. DROSDOWSKY)
Contribution de la dihydrotestostérone au comportement sexuel masculin

C.S. Mantzoro, E.I. Georgiadis, D. Trichopoulos

Unité d'Endocrinologie de l'Hôpital militaire

d'Athènes (Grèce) et Département d'épidémiologie de l'Ecole de Santé Publique d'Harvard, Boston

(USA

BMJ, 20 mai 1995, vol. 310, 1289-1291.

Chez l'homme, de nombreuses études ont montré que le traitement des hypogonadismes par la testostérone améliore libido et fonction sexuelle. On ignore cependant si cet effet bénéfique est dû à la testostérone elle-même ou à la dihydrotestostérone. Nous avons recherché chez de nombreuses recrues de l'armée grecque, l'influence de divers stéroïdes sexuels sur la fonction sexuelle exprimée par la fréquence des orgasmes.

\section{Sujets et méthodes}

Nous avons étudié 100 jeunes sujets volontaires, âgés de 18 à 22 ans qui ont accepté de subir une prise de sang (entre $9 \mathrm{H}$ et $11 \mathrm{H}$ du matin) et de répondre à un questionnaire, le premier jour de leur incorporation dans l'armée.

Parmi d'autres informations sur le mode de vie, le statut social et divers paramètres physiques, le questionnaire faisait préciser le nombre d'orgasmes par semaine au cours du dernier mois. Il a été bien annoncé aux participants que la question était d'indiquer le nombre d'orgasmes indépendamment de la façon dont il avaient été obtenus (coït, masturbation, orgasmes nocturnes).

Ont été dosés dans le sang : la testostérone, la dihydrotestostérone, l'estradiol, l'estrone, la $\Delta 4$ androsténedione et la SBG.

\section{Résultats}

Le nombre moyen d'orgasmes était de 3,9 par semaine.

Seuls l'âge et la dihydrostestostérone avaient une corrélation positive avec le nombre d'orgasmes.

Une différence d'âge de 3 ans correspondait à une augmentation de 2 orgasmes par semaine.

Une augmentation du taux de dihydrotestostérone de la moitié $(1,36 \mathrm{nmol} / \mathrm{l})$ de la valeur moyen- 
ne $(2,37 \mathrm{nmol} / 1)$ correspondait à une augmentation d'au moins un orgasme par semaine.

\section{Discussion}

Nos résultats sont en faveur d'un rôle déterminant de la dihydrotestostérone sur la fonction sexuelle masculine telle qu'elle se réfléchit dans la fréquence des orgasmes.

L'influence de l'âge, dans les limites de la population étudiée, paraît refléter l'augmentation des opportunités (y compris le mariage qui n'a pas été envisagé dans notre étude).

\section{Commentaires : J.C. CZYBA}

Cette publication aura certainement et rapidement beaucoup de succès. L'auteur du commentaire, avant de lire le BMJ, a été informé de la découverte de «l'hormone du plaisir sexuel» par la chronique matinale de Philippe Meyer à France Inter.

Il est à craindre que l'on assiste, dans les prochains mois, à l'entrée en force de la DHT dans la panoplie des aphrodisiaques et les prescriptions des sexologues.

Ceci étant dit, il y a quelques raisons de douter de la rigueur de la méthodologie et du raisonnement tenu, malgré l'intervention statistique $d u$ département d'épidémiologie de Harvard.

Le titre lui-même est discutable. L'orgasme n'est pas un comportement sexuel mais une réaction sexuelle. Etablir sa fréquence n'est pas évaluer un comportement mais, au mieux, estimer l'intensité d'une libido. Donc, la DHT pourrait avoir quelque rapport avec le désir sexuel. Ce constat, s'il était confirmé, remettrait radicalement en cause l'opinion établie que le désir sexuel est conditionné par l'aromatisation de la testostérone en estradiol et non par sa réduction en DHT.

L'unique mesure du taux sanguin de DHT, assortie d'un questionnaire sur le nombre d'orgasmes dans le mois précédant la mesure, permet-elle d'affirmer que le taux de DHT détermine la fréquence des orgasmes, plutôt que le contraire?

Quant au rôle de l'âge, on peut considérer qu'il n'est pas ici l'objet d'une analyse sérieuse, puisque les auteurs se bornent à évoquer une "augmentation des opportunités» qu'ils n'ont, au reste, pas cherché à évaluer.

Attendons de nouvelles recherches.

\section{Fertilité des hommes exposés in utero au diethylstilbestrol}

Wilcox A.J., BaIRD D.B., WeINBERG C.R., Horsnby P.P., HERBSt A.L.

National Institute of environmental Health Science, Science Center (Université de Virginia) et Département d'obstétrique et Gynécologie de l'Université de Chicago.

N. Engl. J. Med. 1995, 332 : 1411-1416.

\section{Introduction}

La fertilité des hommes soumis in utero au DES a été étudiée à partir de la plus vaste cohorte jamais explorée celle de Dieckmann [1] du Chicago Lying In Hospital, qui avait entrepris et publié en 1953 une étude en double aveugle randomisée contre placebo concernant les effets du DES sur l'évolution des grossesses des femmes enceintes à risque.

Cette récente investigation était justifiée par la connaissance d'une réduction de la fertilité des femmes exposées in utero au DES et par les études expérimentales qui avaient montré une diminution de la fertilité chez les souriceaux ainsi qu'une augmentation de fréquence des malformations congénitales des organes génitaux après exposition des mères au DES.

\section{Méthode}

Ce sont les garçons nés de femmes traitées par Dieckmann et suivis depuis leur naissance qui ont fait l'objet de cette étude. Sur 693 qui avaient pu être localisés après leur naissance, 548 ont été contactés et 494 ont donné leur accord pour l'investigation qui a été purement téléphonique. Les hommes exposés de cette cohorte avaient été interwievés entre 1974 et 1976 et réinterrogés en 1991 pour la réalisation de cette enquête. $85 \%$ des hommes ont donné le nom de leur partenaire et $98 \%$ de celles-ci ont accepté de répondre.

\section{Résultats}

Les résultats de cette étude exceptionnelle sont particulièrement favorables. Aucune réduction de la fertilité des hommes nés de mères ayant reçu du DES par rapport aux témoins non exposés, nés de mères de la cohorte qui avaient reçu le placebo, n'a été mise en évidence. 
En revanche, parmi les 253 hommes exposés, des anomalies congénitales des organes génitaux existaient 3 fois plus souvent que parmi les 241 hommes non exposés. Les malformations étaient 2 fois plus fréquentes lorsque la mère avait commencé à prendre le DES avant la 11ème semaine de la grossesse que lorsqu'elle avait commencé son traitement après.

Néanmoins, les hommes atteints de malformations : principalement kystes épididymaires et testicules hypoplasiques ou «autres» (ces malformations étaient décrites par téléphone aux enquêteurs qui les interrogeaient) étaient aussi fertiles que les autres hommes.

Cette appréciation de la fertilité masculine était jugée sur de nombreux critères : engendrement d'au moins une grossesse, âge à la naissance du premier enfant, nombre moyen d'enfants, diagnostic médical d'un trouble de la fertilité, enfin temps pour concevoir le dernier enfant de la partenaire féminine après arrêt de la contraception. En outre, aucune altération de la fonction sexuelle n'a été retrouvée chez les hommes exposés (âge au premier rapport, fréquence des rapports, activité sexuelle avec un partenaire masculin).

Les deux cohortes d'homme et celles de leurs mères étaient similaires à tout point de vue en particulier en ce qui concerne la semaine de grossesse de début de traitement, quoique les hommes exposés lors de l'interwiew étaient plus souvent mariés que les non exposés, 75 contre $69 \%$.

Le détail des pertes de vue est donné avec précision puisque selon les auteurs eux-mêmes, ce résultat tout à fait favorable n'est valable que si cette enquête ne souffre pas de biais majeur.

\section{Commentaire : J. BELAISCH}

Les dossiers de l'Hôpital Lying In de Chicago qui avaient démontré l'inefficacité du DES dans la prévention des avortements spontanés, d'une façon aussi parfaite que non prise en compte par la communauté internationale qui avait imperturbablement continué à prôner l'administration de DES aux femmes enceintes, ont donc été utilisés pour analyser les effets de DES sur l'appareil génital masculin des garçons exposés. Cette publication est un modèle d'étude.

La démonstration avait été apportée par la même équipe, et confirmée par de nombreuses autres enquêtes des effets nocifs sur l'appareil génital féminin des femmes exposées et des difficultés de reproduction qu'elles rencontrent : fréquence augmentée des FCS, accouchements prématurés, morts fotales et périnatales. L'étude des mâles avait également été entreprise et publiée en 1979 par Gill [2].

Cette étude avait montré une augmentation de fréquence de la cryptorchidie, des hypoplasies testiculaires de malformations épididymaires et des altérations du sperme chez les garçons exposés. Mais la fertilité des hommes, qui pour la plupart étaient trop jeunes lors de l'enquête, n'avait pas été analysée. Les anomalies observées concordaient avec la réduction de la pénétration des oeufs de hamster par le sperme des hommes exposés observée par Stenchever [3] dans un travail préliminaire.

Cependant les études plus récentes de Leary [4] et de Shy [5] ne montraient pas d'effets de l'exposition des garçons au DES.

Tous les biais possible de sélection des sujets ont été analysés par les auteurs qui concluent à leur validité : en outre la connaissance de leur état par ces hommes ne pouvait que les pousser à craindre une baisse de leur fécondité et à faire découvrir davantage d'anomalies.

Un seul biais n'est pas évoqué, c'est celui d'un réduction génétique de lafertilité des sujets témoins non exposés, parce qu'ils étaient nés de femmes souffrant de troubles de la fertilité (avortements spontanés principalement), cette réduction n'étant pas aggravée par l'exposition au DES. Mais l'étude anglaise (Lilford $R$ [6]) sur la fertilité des parents des hommes consultant pour infertilité, n'a pas montré de réduction de la fertilité des sœurs, alors que les frères avaient une baisse démontrée de la fertilité. On peut donc en conclure que les altérations de la fertilité féminine ne sont pas associées à des altérations de la fertilité masculine! En outre, il n'est pas mentionné que la fertilité des témoins était grossièrement inférieure à la moyenne nationale, ce que cette hypothèse impliquait.

On peut retenir de cette publication rassurante qu'il est très improbable qu'une étude aussi vaste que celle-ci soit jamais réalisée pour en infirmer les résultats! Aux USA, les hommes exposés ont généralement déjà complété leur famille. En France, il n'en est pas ainsi, cette étude contribuera à apaiser leurs inquiétudes éventuelles. 
On doit ajouter que cette exposition à des doses notables d'cestrogènes n'a provoqué aucune tendance particulière à l'homosexualité ou aux troubles de l'orientation sexuelle, fait qui a un grand intérêt dans le domaine de l'explication hormonale souvent proposée de ces troubles.

\section{BIBLIOGRAPHIE}

1. Dieckmann W.J, Davis M.E., TYnkiewicz L.M., PotTINGER R.E. : Does the administration of diethylstilbestrol during pregnancy have therapeutic value ? I. An. J. Obstet. Gynecol. 66 : 1062-1081, 1953.

2. GILl W.B., Schumacher G.F.B., Bibbo M., Strauss F.H., ScwhoENBERG H.W. : Association of diethylstilbestrol exposure in utero with cryptorchidism, testicular hypoplasia and semen abnormalities. J. Urol. 122 : 36-39, 1979.

3. STENChever M.A., Williamson R.A., Leonard J. ET $\mathrm{AL}$ : Possible relationship between in utero diethylstildoestrol exposure and male fertility. Am. J. Obstet. Gynecol. 140 : 186-193, 1981.

4. LEARY F.J., Ressiguie L.J., KurLand L.T., O'Brien P.C., EMslander R.F., Nolder K.L. : Males exposed in utero to diethylstilbestrol. Jama. $252: 2984$ 2989, 1984.

5. Sky K.K., Stenchever M.A., Karp L.E., Berger R.E., Williamson R.A., LEONARD J. : Genital tract examinations and zona free hamster egg penetration tests from men exposed in utero to diethylstilbestrol. Fertil. Steril. 42 : 772-778, 1984.

6. Lilford R., JoNes A.M., Bishop T., Thornton J., MUELLER : Case control study of wether subfertility in men is familial. BMJ $309: 570-573,1994$.

\section{IMMUNOLOGIE}

\section{Relation entre hypertension artérielle de la grossesse et durée des rapports sexuels avant la conception}

\author{
P.Y. Robillard, T.C. Hulsey, J. Perianin, E. \\ JANKY, E.H. MIRI, E. PAPERNIK
}

Département de gynécologie obstétrique, Hôpital de Pointe à Pitre, Guadeloupe, France ; Université Médicale de Caroline du Sud, Charleston, Etats-Unis.

The Lancet, V 344, 973-975, 8 Oct. 1994.

\section{Introduction}

L'hypertension artérielle de fin de grossesse est classiquement l'apanage des primipares.

Des travaux ont montré que cette hypertension artérielle pouvait être associée avec un changement de partenaire. Dans ce cas, multipares et nullipares ont le même risque d'hypertension.

Le génome paternel code pour le développement précoce du placenta. Les antigènes HLA paternels sont exprimés à la surface des cellules placentaires. L'hypothèse la plus classiquement admise dans la génèse de cette hypertension est une réaction immunitaire dirigée contre les sites antigéniques paternels. Si l'hypertension est d'origine immunitaire, son incidence doit être en relation avec le temps d'exposition aux antigènes paternels.

\section{Patients et méthode}

De février 1993 au 31 juillet 1993, un questionnaire a été rempli par les patientes accouchant à l'Hôpital Universitaire de Pointe à Pitre. Les patientes étaient questionnées à la visite pédiatrique obligatoire, par deux pédiatres qu'elles n'avaient jamais rencontrés pendant la grossesses. Les pères des enfants n'étaient pas présents durant cet interrogatoire. Il était demandé aux femmes si le père de l'enfant actuel était le même que celui des enfants précédents. La durée des rapports sexuels était définie comme la période écoulée entre le premier rapport sexuel jusqu'à la date de la dernière période menstruelle. 
L'hypertension gravidique était définie par une diastolique supérieure à $9 \mathrm{~mm} \mathrm{Hg}$ à deux reprises et associées à une protéinurie supérieure à ++ à la bandelette. L'hypertension maternelle chronique était définie comme une diastolique supérieure à $9 \mathrm{~mm} \mathrm{Hg}$ à deux reprises et avant 20 semaines de gestation. Une analyse statistique a été confiée aux tests $\mathrm{T}$ de Student afin de comparer les caractéristiques cliniques et démographiques des deux groupes.

\section{Résultat}

1011 grossesses ont été incluses. 855 normotensives et 102 hypertensions artérielles dont 19 pré-éclampsies, 2 éclampsies et 54 hypertensions chroniques. Sur les 957 femmes retenues, 252 étaient des primipares, et 705 des multipares, dont 200 avec un nouveau partenaire. L'incidence d'hypertension artérielle était de $11,9 \%$ parmi les primipares, versus $4,7 \% \mathrm{chez}$ les multipares qui n'avaient pas changé de partenaire et $24 \%$ chez les multipares ayant changé de partenaire. La durée des rapports sexuels sans conception avant la grossesse était significativement plus courte chez les hypertendues (Tableau 1).

Chez les primipares l'incidence de l'hypertension artérielle diminue avec l'augmentation de la durée de rapports sexuels sans conception (Tableau 2).

\section{Discussion}

Cette étude confirme les études précédentes qui avaient suspecté une relation entre changements de paternité et hypertension artérielle parmi les multipares. Le risque de voir se développer une hypertension artérielle de fin de grossesse chez les primipares et les multipares est inversement proportionnel avec la durée des

Tableau 1 : Caractéristiques des patientes.

\begin{tabular}{lccc}
\hline & hypertension & TA normale & p \\
\hline Primipares (n) & 30 & 222 & \\
Age Maternel & $23-3(16-38)$ & $23-4$ & $\mathrm{NS}^{*}$ \\
$\begin{array}{l}\text { Moyenne des rapports sexuels } \\
\text { (mois) }\end{array}$ & $2-4$ & 17 & $0001 \ddagger$ \\
Multipares & & & \\
Age maternel & 72 & 633 & $\mathrm{NS} \dagger$ \\
Parité & $29-2(20-35)$ & $28-8(17,43)$ & $\mathrm{NS} \dagger$ \\
Nouveau partenaire & $3-6(2-12)$ & $3-4(2-3)$ & $0001^{*} \ddagger$ \\
Moyenne des rapports sexuels & $48(66-7)$ & $152(24-1)$ & \\
avec le nouveau partenaire (mois) & & & \\
\hline
\end{tabular}

NS $=$ non significatif $f^{*}=X 2,+=$ test $t$ de student,$\neq=$ test moyenne.

Tableau 2 : Durée des rapports sexuels avant la conception.

\begin{tabular}{lcccc}
\hline $\begin{array}{l}\text { Durée des rapports } \\
\text { sexuels (mois) }\end{array}$ & $\mathbf{0 - 4}$ & $\mathbf{5 - 8}$ & $\mathbf{9 - 1 2}$ & $\mathbf{1 2}+$ \\
\hline $\begin{array}{l}\text { Primipares (n=252) } \\
\text { \% avec HTA }\end{array}$ & $16 / 50(32)$ & $6 / 30(20)$ & $3 / 24(13)$ & $5 / 148(3-0)$ \\
RR (95\% CI) & $9-2(3.5-23.9)$ & $5.8(1.9-18)$ & $3.6(0.94-14-3)$ & 1.0 \\
& & & \\
Multipares (n=705) & $26 / 54(48)$ & $9 / 34(26)$ & $4 / 22(18)$ & $33 / 595(6)$ \\
\% avec HTA & $8-6(6.6-13.5)$ & $4.7(2.5-9.1)$ & $3.2(1.2-8.4$ & 1.0 \\
RR $(95 \%$ CI) & & & $38 / 743(5)$ \\
Population totale (n=957) & $42 / 104(40)$ & $16 / 64(23)$ & $7 / 46(15)$ & $1-0$ \\
\% avec HTA & $7.8(5.3-11,5)$ & $4.5(2.6-7.8)$ & $2.9(1.4-6.2)$ & \\
RR $(95 \%$ CI)* & & & & \\
\hline
\end{tabular}

$R R=$ risque relatif 
rapports sexuels. Ce risque n'est pas modifié par l'âge maternel, le niveau socio-économique, le nombre de grossesses.

L'hypertension artérielle du troisième trimestre est certainement d'origine immunitaire : durant les rapports sexuels, les femmes développent une réponse immunitaire contre les antigènes spermatiques. La présence d'anticorps anti-spermatiques n'est pas retrouvée chez les femmes vierges ou chez les femmes utilisant une contraception par préservatifs. Il y a sûrement d'autres facteurs à prendre en compte dans le développement de ces hypertensions. Il est cependant à noter que dans cette série, l'incidence de l'hypertension chute de $10,6 \%$ à $5,1 \% \mathrm{chez}$ les femmes ayant eu des rapports sexuels non protégés durant plus de un an avant la conception.

Si ces données sont confirmées, ces résultats pourraient avoir une implication dans la prévention de l'hypertension artérielle gravidique.

\section{Commentaire : (B. SALLE)}

Ce travail de recherche clinique à la frontière de l'immunologie, de l'obstétrique et de l'andrologie, est le premier à mettre en évidence une relation entre hypertension gravidique et rapport sexuel. L'hypertension gravidique voit sa génèse se developer au cours du premier trimestre. Les cellules trophoblastiques n'envahissent pas la vascularisation utérine et les parois artérielles ne sont pas détruites. L'hypovascularisation placentaire induit des mécanismes compensatoires dont l'hypertension. La tolérance du système immunitaire permet la colonisation trophoblastique. Un des meilleurs mécanismes de tolérance est l'exposition répétée à de petites doses d'antigène. Il semble possible que l'exposition repétée aux antigènes spermatiques aux cours des rapports sexuels puisse induire cette tolérance.

Cette théorie immunitaire est à mettre en parallèle avec la théorie idiotypique antiidiotypique mise en évidence par Naz. Les infertilités immunologiques feminines pourraient provenir d'un déséquilibre entre réaction anticorps et antianticorps.

\section{FECONDATION IN VITRO}

Le résultat de l'injection intracytoplasmique du spermatozoïde n'est en relation avec aucun des trois principaux paramètres du spermogramme

Z.P. NAGY, J. LiU, H. JoRIS, G. Verheyen, H. Tournaye, M. Camus, M.P. Derde, P. Devroey, A.C. VAN STEIRTEGHEM.

Centre de Médecine de la Reproduction et Département de Biostatistique. Hôpital Univesitaire de L'Université de Bruxelles -Belgique.

Human.Reprod., 10, (5), 1123-1129, 1995.

\section{But}

Déterminer si les facteurs classiques du spermogramme ont une valeur prédictive sur les chances de grossesse en ICSI.

Etude rétrospective sur 966 cycles.

\section{Matériel et méthode}

1) Indication de l'TCSI

- échec de fécondation en FIV classique

- fécondation faible en FIV classique

- sperme très pauvre $(<500.000 \mathrm{spz}$ mobiles progressifs/éjaculat)

2) Stimulation ovarienne : GnRHa + HMG

3) Insémination : ICSI

4) Groupe A : NUMERATION

Num. 1 - pas de spz à l'examen direct

Num. 2 - nbre total de spz $>0--->1 \times 10^{6}$

Num. 3 - nbre total de spz $>1-->5 \times 10^{6}$

Num. 4 - nbre total de $\mathrm{spz}>5 \times 10^{6}$

Groupe B : MOBILITE

Mob. 1 - spz immobiles uniquement

Mob. 2 - quelques spz mobiles

Mob. 3 - > 0 ----> 24\% spz mobiles

Mob. 4 - > 24---> 50\% spz mobiles

Mob. 5 - > 50\% spz mobiles 
Groupe C : MORPHOLOGIE (selon Kruger)

Morpho. 1- 0\%

Morpho. 2- 1-----> $\leq 3 \%$

Morpho. 3- 4-----> 13\%

Morpho. 4-> 13\%

\section{Résultats}

Les auteurs signalent que les taux de fécondation sont significativement réduits dans les groupes Num.1, Mob.1 et 2. Ils attribuent les résultats exécrables du groupe Mob.1 au fait qu'ils n'ont pas pu vérifier si les spermatozoïdes immobiles injectés n'étaient pas des spermatozoïdes morts.

La tératospermie ne semble pas influencer les résultats en ICSI mais il faut signaler que le biologiste opère une sélection dans le choix du spermatozoïde qu'il va injecter. De plus, les auteurs n'ont pas observé d'augmentation du taux de fausses couches précoces.

Une étude corrélative révèle l'existence d'une relation directe entre la mobilité et le taux de fécondation alors que celle-ci est très faible pour la numération et la morphologie. les auteurs concluent que l'ICSI résoud tous les problèmes d'oligo-asthéno-tératospermie quelle que soit leur gravité à l'exception de l'absence de mobilité. Dans ce cas il est impératif de trouver les spermatozoïdes vivants.

\section{Commentaires : (A. DEMOULIN)}

La lecture de ces résultats laisse l'andrologue pantois. Est-il, en 1995, encore honnête de proposer à l'homme infertile des explorations sophistiquées et coûteuses? Peut-on encore justifier des traitements médicaux ou chirurgicaux dont on connaît l'habituelle inefficacité ? Il faut cependant reconnaître et admettre que seule l'équipe de la V.U.B a, à ce jour, publié des résultats aussi extraordinaires dans des pathologies aussi graves.

D'autre part, aucune étude fondamentale n'a jusqu'à présent démontré l'innocuité à long terme de ces techniques et peut-être regretterons nous demain notre intrépidité et notre participation à cet emballement.

\begin{tabular}{lcccc}
\hline & $\begin{array}{c}\text { Nbre de } \\
\text { cycles }\end{array}$ & $\begin{array}{c}\text { Nbre de } \\
\text { transferts } \\
\text { (\%-taux) }\end{array}$ & $\begin{array}{c}\text { Taux de } \\
\text { fécondation } \\
\text { (par ovo injecté) }\end{array}$ & $\begin{array}{c}\text { Nbre de } \\
\text { grossesses } \\
\text { cliniques } \\
\text { (\%) taux/cycle } \\
\text { ou tansfert) }\end{array}$ \\
\hline Num. 1 & 57 & $49(85 \%)$ & 38.4 & $12(21-24.5)$ \\
Num. 2 & 97 & $93(96 \%)$ & 41.1 & $24(24.7-25.8)$ \\
Num. 3 & 128 & $123(92.5 \%)$ & 43.4 & $27(22-22)$ \\
Num. 4 & 684 & $633(92.5 \%)$ & 44.3 & $190(27.8-30)$ \\
\hline Mob. 1 & 12 & $5(42 \%)$ & 5.0 & $0(0-0)$ \\
Mob. 2 & 54 & $47(87 \%)$ & 36.8 & $6(11.1-12.8)$ \\
Mob. 3 & 19 & $19(100 \%)$ & 40.1 & $\mathbf{6}(31.6-31.6)$ \\
Mob. 4 & 479 & $319(95 \%)$ & 43.3 & $129(29.0-30.8)$ \\
Mob. 5 & 337 & $42(87.5 \%)$ & 46.6 & $83(24.6-26.0)$ \\
\hline Morpho. 1 & 48 & $120(96 \%)$ & 41.8 & $13(27.1-31.0)$ \\
Morpho. 2 & 125 & $288(93.3 \%)$ & 44.0 & $39(31.2-32.5)$ \\
Morpho. 3 & 307 & $193(95 \%)$ & 44.3 & $75(24.4-26)$ \\
Morpho. 4 & 203 & & 46.5 & $56(27.5-29)$ \\
\hline
\end{tabular}




\section{Embryons viables obtenus par injection intra-ovocytaire de spermatides rondes}

\author{
J. Tesarik, C. Mendoza, J. Testart \\ 92292 Neuilly-sur-Seine
}

New.Engl. J.M., v.333, $n^{\circ} 8,525$

Après la publication de Ogura et al. relatant, chez la souris, les résultats positifs de fécondations in vitro par électrofusion d'ovocytes et de spermatides rondes, les auteurs ont envisagé une application à l'espèce humaine.

Dans 12 cas d'azoospermie inexpliquée, des spermatides rondes étaient cependant présentes dans le sperme. Des ovocytes ont été recueillis chez 7 conjointes de ces patients et il a été décidé de tenter de les féconder avec des spermatides.

Les spermatides ont été isolées par centrifugation sur gradient de Percoll (fraction 70\%). Une spermatide a été injectée dans chaque ovocyte par la technique utilisée par les auteurs pour la microinjection d'un spermatozoïde. Une fécondation, attestée par la présence de 2 pronoyaux un jour après l'injection, a été obtenue pour 14 des 39 ovocytes ( $36 \%$ ). Tous ces zygotes présentaient un stade d'au moins 2 cellules 44 heures après l'injection. Un embryon au moins a été transféré chez chacune des 7 femmes. 2 grossesses cliniques ont été obtenues dont l'une a abouti, à la date de la publication, à la naissance d'un garçon de 3kg500 en bonne santé.

Les auteurs concluent, d'une part, que le facteur d'activation de l'ovocyte est déjà contenu dans la spermatide ronde et, d'autre part que lorsque des spermatides rondes sont présentes dans le sperme des azoospermiques, des fécondations sont possibles sans qu'il soit nécessaire de recourir à une intervention urologique.

\section{Commentaires : (J.C.CZYBA)}

Dans Andrologie de décembre 1994, vol.4, $n^{\circ} 4$, j'avais rendu compte (page 532) du travail de Ogura et al. chez la souris et fait quelques commentaires sur diverses implications et conséquences prévisibles de leurs résultats.

Dans le même numéro de notre revue, sous la forme d'une lettre à la rédaction [1], P.Vanderzwalmen et al. font état d'une fécondation et de l'obtention d'un zygote après injection intraovo- cytaire d'une spermatide. La spermatide avait été obtenue par biopsie testiculaire et non directement dans le sperme. Les auteurs ne pouvaient affirmer l'obtention d'une grossesse puisque le zygote avait été transféré en même temps que 3 autres obtenus par microinjection de spermatozoïdes d'origine testiculaire.

L'équipe de Tesarik et Testart est allée plus loin et les résultats présentés démontrent que les spermatides rondes desquamées dans le sperme possèdent toutes les qualités requises pour obtenir une fécondation in vitro par microinjection et la naissance d'un enfant normalement développé et en bonne santé. Ces résultats ont été rapidement largement médiatisés et, bien entendu, ils suscitent des réactions diverses [2].

On a pu regretter l'absence d'une expérimentation animale préalable. Peut être peut-on considérer que le travail de Ogura et al. représente cette expérimentation.

On peut se demander si la loi bioéthique (29.7.1994) qui interdit toute expérimentation sur l'embryon humain s'applique à son mode de conception qui, ici, peut être qualifié d'expérimental.

J. Testart, dans diverses déclarations aux médias, souligne que cette nouvelle technique d'assistance médicale à la procréation devrait contribuer, avec l'ICSI, à réduire notablement la population de couples demandeurs d'Insémination artificielle avec sperme de donneur. Rappelons l'article L.152-6 de la loi bioéthique : "L'assistance médicale à la procréation avec tiers donneur ne peut être pratiquée que comme ultime indication lorsque la procréation médicalement assistée à l'intérieur du couple ne peut aboutir". La loi justifie le recours à l'injection de spermatide.

Pour ma part, d'un point de vue strictement technique, sachant qu'il est quasiment impossible, sans coloration, de distinguer dans le sperme les cellules germinales immatures des leucocytes, je me demande comment les auteurs ont pu sélectionner les spermatides à injecter.

\section{REFERENCES}

1. VANDERZWALMEN P., BERTIN G., NIJS M., LEJEUNE B., SCHOYSMAN R. : Fécondation ovocytaire par spermatide dans un programme de fécondation in vitro. Andrologia, 1994, V.4, $\mathrm{n}^{\circ} 4$, 523-524.

2. BUTLER D : Spermatid injection fertilizes ethics debate. Nature, 1995, V 377, 277. 